

\section{Kalpataru}

Jurnal Sejarah dan Pembelajaran Sejarah

Volume 7, Nomor 1, Juli 2021

\section{Chief Editor}

Drs. Sukardi, M.Pd.

\section{Editor}

Dr. Muhamad Idris, M.Pd.

Eva Dina Chairunisa, M.Pd.

Jeki Sepriady, S.Pd.

\section{Reviewer}

Dr. Tahrun, M.Pd.

Drs. Supriyanto, M.Hum.

Dra. Retno Purwati, M.Hum.

Dr. Nor Huda Ali, M.Ag., M.A.

Dr. Budi Agung Sudarman, S.S., M.Pd.

Dr. Purmansyah, M.A.
(Universitas PGRI Palembang)

(Universitas Sriwijaya Palembang)

(Balai Arkeologi Sumatera Selatan)

(Masyarakat Sejarawan Indonesia Sumsel)

(Balai Bahasa Provinsi Sumatera Selatan)

(Universitas Muhammadiyah Palembang)

\footnotetext{
Alamat Redaksi

Program Studi Pendidikan Sejarah

Fakultas Keguruan dan IImu Pendidikan Universitas PGRI Palembang

Telp. 0711-510043

Email: jurnalkalpatarusejarah@gmail.com

Website: https://jurnal.univpgri-palembang.ac.id/index.php/Kalpa
} 


\section{Kalpataru}

JURNAL SEJARAH DAN

PEMBELAJARAN SEJARAH

Terbit dua kali setahun pada Juli dan Desember

Diterbitkan oleh:

Program Studi Pendidikan Sejarah Jurusan Pendidikan IPS

Fakultas Keguruan

dan IImu Pendidikan

Universitas PGRI Palembang

\section{DAFTAR ISI}

Nilai Budaya Masjid Jami' Sungai Lumpur Kelurahan II Ulu Palembang Sebagai Sumber Pembelajaran Sejarah

Maya Susanti, Muhamad Idris, Aan Suriadi.... $1-9$

Analisis Konsep Gender Dalam Undang-Undang Simbur Cahaya Sebagai Sumber Pembelajaran Sejarah Ruli Annisa, Muhamad Idris, Kabib Sholeh .... $10-18$

Perbedaan Model Pembelajaran Student Teams Achievement Divisions (STAD) dengan Model Pembelajaran Jigsaw Terhadap Hasil Belajar Siswa Pada Mata Pelajaran Sejarah di SMA Negeri 2 Mesuji Taufik Sidiki Al-Haq, Nur Ahyani, Ida Suryani.

Pengaruh Pemanfaatan Media Youtube Terhadap Hasil Belajar Siswa Mata Pelajaran Sejarah di SMK PGRI 2 Palembang

Riska Anggraini, Nur Ahyani, Ida Suryani. 28-36

Pengaruh Metode Pembelajaran Daring Terhadap Hasil Belajar Siswa Pada Mata Pelajaran Sejarah di Kelas XI IPA SMA Shailendra Palembang

Christina Leovita Saragih, Nur Ahyani, Aan Suriadi. $37-42$

Pengembangan Media Pembelajaran Digital Bukti-bukti Bangunan Masjid Kuno di Palembang Berbasis Android Varokah Widiyanti, Eva Dina Chairunisa, Ahmad Zamhari .

\section{Gambar Cover:}

Pohon Kalpataru

Candi Prambanan

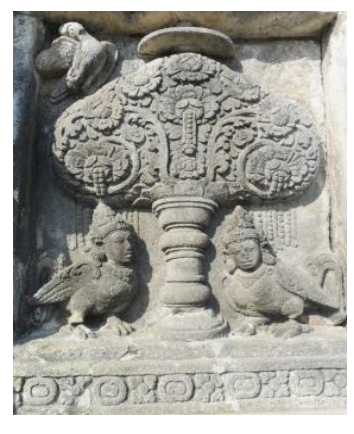

Koleksi: Muhamad Idris
Hubungan Jawa-Melayu Dalam Dunia Arsitektur Melayu Sumatera Selatan Reyvaldi Uyun, Muhamad Idris, Ahmad Zamhari.

Kondisi Politik Orde Baru di Gorontalo Tahun 19681998

Ferrari Yuliawati S, Suryo Ediyono. $61-67$

Nilai-nilai Sejarah dan Budaya Ikonografi Megalith di Lahat Sebagai Sumber Pembelajaran Sejarah Nasional Jainal Arifin, Sukardi, Dina Sri Nindiati.

Minat Siswa Terhadap Sejarah dan Budaya Palembang di SMA Negeri 15 Palembang Febbi Astuti, Muhamad Idris, Kabib Sholeh. $.77-82$ 
Kalpataru, Volume 7, Nomor 1, Juli 2021 (19-27)

\title{
PERBEDAAN MODEL PEMBELAJARAN STUDENT TEAMS ACHIEVEMENT DIVISIONS (STAD) DENGAN MODEL PEMBELAJARAN JIGSAW TERHADAP HASIL BELAJAR SISWA PADA MATA PELAJARAN SEJARAH DI SMA NEGERI 2 MESUJI
}

\author{
Taufik Sidiki Al-Haq \\ Mahasiswa Program Studi Pendidikan Sejarah, FKIP Universitas PGRI Palembang \\ Email: Taufikalhaq02@gmail.com \\ Nur Ahyani \\ Dosen Program Studi Pendidikan Sejarah FKIP Universitas PGRI Palembang \\ Email: nurahyani63@gmail.com \\ Ida Suryani \\ Dosen Program Studi Pendidikan Sejarah FKIP Universitas PGRI Palembang \\ Email: ida954321@gmail.com
}

\begin{abstract}
ABSTRAK
Permasalahan di dalam penelitian ini apakah ada perbedaan model pembelajaran Student Teams Achievement Divisions dengan Jigsaw terhadap hasil belajar siswa pada mata pelajaran sejarah kelas $X$ IPS 1 dan X IPS 2 di SMA Negeri 2 Mesuji tahun pelajaran 2020/2021. Penelitian ini menggunakan dua model pembelajaran yaitu pertama model pembelajaran Student Teams Achievement Divisions sebagai kelas eksperimen 1 yang di perlakukan di kelas XIPS 1 yang kedua model pembelajaran Jigsaw sebagai kelas eksperimen 2 yang di perlakukan di kelas X IPS 2. Pemilihan sampel ini menggunakan teknik sampling secara acak, hasil data diperoleh dari hasil tes, teknik analisis data yang digunakan adalah ujiT. Dari hasil analisis data tes menunjukkan bahwa data berdistribusi normal dan homogenitas. Dari hasil pengujian hasil hipotesis didapat kan thitung $=3,52>$ tabel 1,671 pada taraf signitifikan $5 \%$ dan $d k=\left(n_{1}+\right.$ $n_{2}$ - 2) sehingga dapat diterima. Maka dapat disimpulkan bahwa hasil penelitian ini ada perbedaan model pembelajaran Student Teams Achievement Divisions dengan model pembelajaran Jigsaw terhadap hasil belajar siswa pada mata pelajaran sejarah kelas X di SMA Negeri 2 Mesuji tahun pelajaran 2020/2021.
\end{abstract}

Kata Kunci: Model Pembelajaran Student Teams Achievement Divisions, Model Pembelajaran Jigsaw dan Hasil Belajar.

\section{A. PENDAHULUAN}

Menurut Wahyudin (2007:1) pendidikan adalah humanisasi, yaitu upaya memanusiakan manusia atau upaya membantu manusia agar mampu mewujudkan diri sesuai dengan martabat kemanusiaannya. Selanjutnya, Pendidikan adalah satu-satunya aset untuk membangun sumber daya manusia yang berkualitas. Lewat pendidikan bermutu, bangsa dan negara akan terjunjung tinggi martabat di mata dunia (Shoimin, 2014:20).

Sedangkan Tirtahardja \& Sulo (2005:1) berpendapat pendidikan bermaksud membantu peserta didik untuk menumbuh kembangkan potensi-potensi kemanusiaan. Dalam pendidikan diperlukan model pendidik yang tidak hanya mampu menjadikan peserta didik yang cerdas dalam teori ilmu tetapi juga cerdas dalam praktik ilmu. Pendidikan adalah pembelajaran pengetahuan, keterampilan dan kebiasaan sekelompok orang yang diturunkan dari satu generasi kegenerasi berikutnya melalui pengajaran, penelitian atau pelatihan.

Selain itu pendidikan adalah peran vital sebagai pendorong individu dan warga masyarakat untuk meraih progresifitas pada semua lini kehidupan. Di samping itu, pendidikan dapat menjadi determinan penting bagi proses transformasi personal maupun sosial (Ismaya, 2015:1).

Dari beberapa pendapat para ahli di atas peneliti dapat menyimpulkan bahwa pengertian 
pendidikan adalah upaya membantu manusia agar mampu mewujudkan diri agar sesuai martabat kemanusiaannya, serta membantu peserta didik untuk menumbuh kembangkan potensi-potensi kemanusiaan.

Pembelajaran merupakan suatu sistem yang memiliki peran sangat dominan untuk mewujudkan kualitas pendidikan (Shoimin, 2014:20). Selanjutnya pembelajaran adalah segala sesuatu yang dapat membawa informasi dan pengetahuan dalam interaksi yang berlangsung antara pendidik dengan peserta didik (Pohan, 2020:1).

Dari beberapa pendapat para ahli di atas peneliti dapat menyimpulkan bahwa pembelajaran adalah proses interaksi peserta didik dengan pendidik dan sumber belajar pada suatu lingkungan belajar yang memiliki peran sangat dominan untuk mewujudkan kualitas pendidikan.

Menurut Octavia, (2020:12) model pembelajaran adalah suatu deskripsi dari lingkungan pembelajaran, termasuk perilaku guru menerapkan dalam pembelajaran. Model pembelajaran banyak kegunaannya mulai dari perencanaan pembelajaran dan perencanaan kurikulum sampai perencanaan bahan-bahan pembelajaran, termasuk program-program multimedia.

Selanjutnya, model pembelajaran adalah pola atau rencana yang sudah direncanakan sedemikian rupa dan digunakan untuk menyusun kurikulum, mengatur materi pembelajaran dan memberi petunjuk kepada pengajar di kelasnya. Dalam penerapannya model pembelajaran yang digunakan harus sesuai dengan kebutuhan siswa (Isjoni, 2014:50). Model pembelajaran adalah seluruh rangkaian penyajian materi ajar yang meliputi segala pembelajaran yang dilakukan guru serta segala fasilitas yang terkait yang digunakan secara langsung atau tidak langsung dalam proses belajar mengajar.

Berdasarkan masalah yang telah ditemukan, hasil wawancara dan observasi yang telah dilaksanakan oleh peneliti terhadap guru mata pelajaran sejarah di SMA Negeri 2 Mesuji. Bahwa hasil belajar siswa masih sangat rendah, dibuktikan dengan hasil $13 \%$ siswa atau 9 siswa dari seluruh siswa kelas $X$ yang belum berhasil mencapai Kriteria Ketuntasan Minimal (KKM) yang ditentukan sekolah yaitu 78 .

Rendahnya hasil belajar tersebut disebabkan oleh guru yang masih menggunakan metode ceramah, metode diskusi dan metode tanya jawab, terbatasnya fasilitas sekolah kurang tersedianya buku mata pelajaran sejarah, sehingga menyebabkan siswa kurang aktif dalam mengajukan pertanyaan atau pendapat serta menjawab pertanyaan dalam proses belajar mengajar, sehingga proses belajar mengajar hanya didominasi oleh guru dan saat mengikuti proses belajar mengajar, tidak semua siswa paham dengan materi yang disampaikan guru dalam mengikuti proses pembelajaran.

Hasil ulangan akhir semester mata pelajaran sejarah siswa kelas X IPS semester ganjil di SMA Negeri 2 Mesuji tahun pelajaran 2020/2021 dengan KKM 78 dengan hasil nilai ada beberapa siswa yang tidak mencapai nilai KKM yaitu siswa kelas X IPS 1 dengan jumlah siswa 34 dengan 30 siswa mencapai KKM dan 4 siswa yang tidak mencapai KKM. Dengan siswa kelas X IPS 2 dengan jumlah siswa 32 dengan siswa yang mencapai KKM 31 dan 3 siswa yang belum mencapai nilai KKM.

Maka untuk meningkatkan proses belajar mengajar sehingga diperlukannya model pembelajaran, yang mana model pembelajaran harus bervariasi sehingga siswa tidak merasa bosan. Dalam penelitian ini, peneliti akan menggunakan model pembelajaran Student Teams Achievement Divisions (STAD) dengan model pembelajaran Jigsaw, diharapkan mampu meningkatkan hasil belajar siswa kelas $X$ dalam mencapai Kriteria Ketuntasan Minimal (KKM).

Model pembelajaran yang akan digunakan dalam penelitian ini adalah model pembelajaran Student Teams Achievement Divisions (STAD) dengan model pembelajaran Jigsaw. Model pembelajaran Student Teams Achievement Divisions (STAD) adalah suatu model pembelajaran yang merupakan salah satu tipe kooperatif yang menekankan pada adanya aktivitas dan interaksi di antara siswa untuk saling memotivasi dan saling membantu dalam menguasai materi pelajaran guna 
mencapai prestasi yang maksimal (Isjoni, 2014:51).

Sedangkan model pembelajaran Jigsaw adalah salah satu tipe pembelajaran kooperatif yang mendorong siswa aktif dan saling membantu dalam menguasai materi pelajaran untuk mencapai prestasi yang maksimal (Isjoni, 2014:54).

\section{B. METODE PENELITAN}

\section{Teknik Pengumpulan Data}

Menurut Sugiyono (2012:193) teknik pengumpulan data adalah langkah yang paling utama dalam melakukan penelitian, karena tujuan utama dalam penelitian adalah mendapatkan data. Jadi teknik yang digunakan dalam pengumpulan data ini adalah teknik tes dan dokumentasi.

\section{Tes}

Menurut Arikunto (2013:193) berpendapat, tes adalah serentetan pertanyaan atau latihan serta alat lain yang digunakan untuk mengukur keterampilan, pengetahuan, inteligensi, kemampuan atau bakat yang dimiliki oleh individu atau kelompok.

Tes yang digunakan pilihan ganda agar peserta didik lebih tertarik dalam mengerjakaan soal karena jawaban dari pilihan ganda tersebut bervariasi sehingga peserta didik tidak merasa bosan dalam proses belajar. Soal pilihan ganda berjumlah 20 butir dengan soal sesuai dengan materi yang telah dipelajari.

\section{Dokumentasi}

Menurut Arikunto (2013:201) berpendapat, dokumentasi dari asal katanya dokumen, yang artinya barang-barang tertulis. Di dalam melaksanakan metode dokumentasi peneliti menyelidiki benda-benda tertulis seperti buku-buku, majalah, dokumen peraturanperaturan, notulen rapat, catatan harian dan sebagainya.

Dokumentasi ini digunakan untuk mendapatkan data tentang jumlah siswa dan hasil belajar mata pelajaran sejarah dengan menerapkan dua model pembelajaran yaitu perbedaan model pembelajaran Student Teams Achievement Division dengan model pembelajaran Jigsaw pada mata pelajaran sejarah kelas $X$ di SMA Negeri 2 Mesuji tahun pelajaran 2020/2021. Selain itu, dokumentasi dilakukan untuk mengetahui kegiatan apa saja yang dilakukan selama penelitian yang telah dilampirkan dalam bentuk foto, nilai, daftar hadir, soal tes dan lain-lainnya dalam kegiatan belajar mengajar dengan model pembelajaran Student Teams Achievement Division dengan model pembelajaran Jigsaw.

\section{HASIL DAN PEMBAHASAN}

Penyampaikan materi pada Kelas X IPS 1 lebih menyenangkan hal ini dilihat dari aktivitas belajar siswa yang diperoleh di kelas eksperimen 1 menggunakan model pembelajaran Student Tems Achievement Divisions (Stad). Pada kelas eksperimen 1 siswa dapat menunjukkan keaktifan dalam proses belajar. Hal ini dapat dilihat bahwa proses belajar dengan menggunakan model pembelajaram Student Tems Achievement Divisions (STAD), membuat siswa merasa senang karena setiap siswa diajak untuk aktif dalam berkelompok. Guru memberikan kesempatan kepada siswa untuk terlibat secara aktif dan bekerja sama dalam proses pembelajaran dalam mengekspresikan gagasan/pikiran mereka, dan menjadikan pembelajaran lebih bermakna. Maka dapat disimpulkan bahwa penggunaan model pembelajaran Student Tems Achievement Divisions (STAD) dapat meningkatkan hasil belajar siswa.

Pada kelas eksperimen 2 penyampaian materinya di kelas X IPS 2 menggunakan model pembelajaran Jigsaw, semua siswa terlihat kurang bersemangat dalam mengikuti proses pembelajaran. Hal ini dibuktikan dengan aktivitas di kelas eksperimen 2. Maka dapat disimpulkan bahwa hasil belajar siswa menggunaan model pembelajaran Jigsaw lebih rendah dibandingkan kelas eksperimen 1.

\section{Hasil Analisis Data \\ Uji Normalitas Data}

Uji normalitas data dilakukan untuk mengetahui apakah data yang akan digunakan normal atau tidak. Sebab uji statistik baru bisa digunakan apabila data tersebut terdistribusi normal. Sebelum dilakukan uji normalitas, data 
terlebih dahulu disusun ke dalam daftar distribusi frekuensi, kemudian menentukan ratarata nilai $(\bar{X})$, simpangan $(\mathrm{S})$, dan modus $\left(\mathrm{M}_{0}\right)$.

Selanjutnya dari hasil perolehan rata-rata standar deviasi (S) dan modus $\left(\mathrm{M}_{0}\right)$ data tersebut diuji kenormalannya dengan rumus kemiringan Kurva Karl Pearson. Data dapat dilakukan terdistribusi normal apabila $\mathrm{Km}$ terletak diantara (-1) dan (1).

\section{Hasil Uji Normalitas Data Kelas Eksperimen 1}

Data nilai akhir kelas eksperimen yaitu dibuat daftar distribusi frekuensi guna menghitung rata-rata dan simpangan baku. Adapun langkah-langkah yang tempuh adalah sebagai berikut:

a. Menghitung hasil tes dari yang paling rendah sampai paling tinggi

$\begin{array}{lllll}55 & 65 & 65 & 70 & 75 \\ 75 & 80 & 80 & 80 & 80 \\ 80 & 80 & 80 & 85 & 85 \\ 85 & 85 & 85 & 85 & 85 \\ 85 & 85 & 85 & 85 & 90 \\ 90 & 90 & 90 & 95 & 95 \\ 95 & 95 & 95 & & \end{array}$

b. Rentang = Nilai terbesar - Nilai terkecil $=95-55$ $=40$

c. Banyak kelas interval

$=1+3,3 \log n$

$=1+3,3(\log 34)$

$=1+3,3(1,53)$

$=6,04$ atau 6

Jadi, banyak kelas yang diambil 6 (enam) kelas.

d. Panjang kelas interval

$=\frac{\operatorname{Re} n \tan g}{\text { Banyakkelas }}$

$=\frac{40}{6}$

$=6,66$ atau 7

Jadi, panjang kelas yang diambil 7 (tujuh). e. Membuat tabel distribusi frekuensi

Tabel 1

Distribusi Frekuensi Nilai Kelas

Eksperimen 1

\begin{tabular}{|c|c|c|c|c|c|}
\hline Interval & $\mathbf{f}_{\mathbf{i}}$ & $\mathbf{x}_{\mathbf{i}}$ & $\mathbf{f}_{\mathbf{i}} \mathbf{x}_{\mathbf{i}}$ & $\mathbf{x i}_{\mathbf{i}}{ }^{\mathbf{2}}$ & $\mathbf{f}_{\mathbf{i}} . \mathbf{x}_{\mathbf{i}}{ }^{\mathbf{2}}$ \\
\hline $55-61$ & 1 & 58 & 58 & 3364 & 3364 \\
\hline $62-68$ & 2 & 65 & 130 & 4225 & 8450 \\
\hline $69-75$ & 3 & 72 & 216 & 5184 & 15552 \\
\hline $76-82$ & 7 & 79 & 553 & 6241 & 43687 \\
\hline $83-89$ & 11 & 86 & 946 & 7396 & 81356 \\
\hline $90-96$ & 10 & 93 & 930 & 8649 & 86490 \\
\hline Jumlah & 34 & 453 & 2833 & 35059 & 238899 \\
\hline
\end{tabular}

Sumber: Pengolahan data primer 2018

Dari tabel dan distribusi frekuensi hasil belajar kelas eksperimen tersebut dapat dilihat frekuensi nilai dari tiap-tiap kelas interval kelas eksperimen dan nilai tengah dari tiap-tiap kelas interval yang memiliki frekuensi $\left(f_{i}\right)$ paling banyak terdapat pada kelas 83 - 89 sebanyak 11 siswa sedangkan untuk kelas yang memiliki frekuensi terendah terletak pada kelas 55 - 61 sebanyak 1 siswa, berikut data dalam diagram batang:

\section{Gambar 1}

\section{Diagram Distribusi Frekuensi Hasil Belajar Kelas Eksperimen 1}

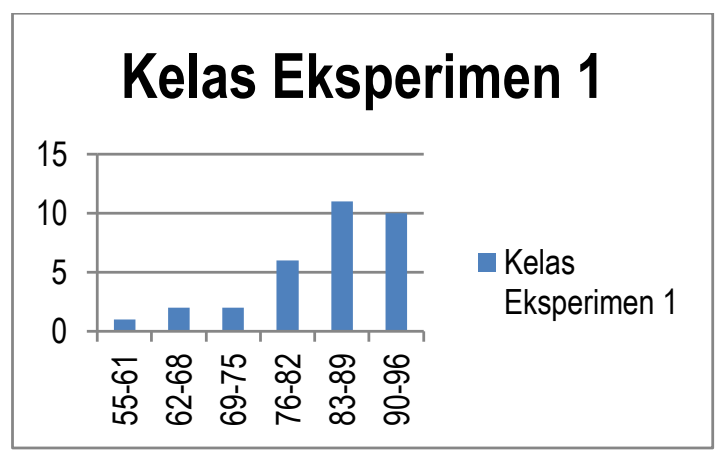

Nilai Kelas Interval

f. Nilai rata-rata kelas eksperimen

$$
\begin{aligned}
\bar{x} & =\frac{\sum f i x i}{\sum f i} \\
& =\frac{2833}{34} \\
& =83,32
\end{aligned}
$$


g. Mencari modus kelas eksperimen

$$
\begin{aligned}
M o & =b+p\left[\frac{b 1}{b 1+b 2}\right] \\
b & =83-0,5=82,5 \\
p & =11 \\
b 1 & =11-7=4 \\
b 2 & =11-10=1 \\
M o & =82,5+7\left[\frac{4}{4+1}\right] \\
M_{0} & =82,5+7\left[\frac{4}{5}\right] \\
M_{0} & =82,5+7(0,8) \\
M_{0} & =82,5+5,6 \\
M_{0} & =88,1
\end{aligned}
$$

h. Mencari simpangan baku kelas eksperimen

$$
\begin{aligned}
S^{2} & =\frac{n \sum \mathrm{f}_{1} \mathrm{x}_{1}{ }^{2}-\left(\sum \mathrm{f}_{1} \mathrm{x}_{1}\right)^{2}}{n(n-1)} \\
S^{2} & =\frac{34(238899)-(2833)^{2}}{34(34-1)} \\
S^{2} & =\frac{8122566-8025889}{1122} \\
S^{2} & =\frac{96677}{1122} \\
S^{2} & =86,16 \\
S^{2} & =\sqrt{86,16} \\
S^{2} & =9,28
\end{aligned}
$$

Dari rata-rata, modus, dan simpangan baku maka dapat dicari koefisien kemiringan kurva dengan menggunakan rumus Karl Pearson, yaitu:

$$
\begin{aligned}
& \mathrm{Km}=\frac{\bar{X}-M_{O}}{S} \\
& \mathrm{Km}=\frac{83,32-88,1}{9,28} \\
& \mathrm{Km}=\frac{-4,78}{9,28} \\
& \mathrm{Km}=-0,51
\end{aligned}
$$

Dari perhitungan uji normalitas data di atas, nilai $\mathrm{Km}$ adalah $-0,51$ dan $\mathrm{Km}$ terletak diantara (-1) dan (1), maka data kelas eksperimen dapat dikatakan terdistribusi normal.

\section{Hasil Uji Normalitas Data Kelas Eksperimen} 2

Data nilai akhir kelas eksperimen 2 yaitu dibuat daftar distribusi frekuensi guna menghitung rata-rata dan simpangan baku.
Adapun langkah-langkah yang tempuh adalah sebagai berikut:

a. Menghitung hasil tes dari yang paling tinggi samapai paling terendah

$\begin{array}{lllll}55 & 60 & 65 & 65 & 65 \\ 65 & 70 & 75 & 75 & 75 \\ 75 & 75 & 75 & 75 & 80 \\ 80 & 80 & 80 & 80 & 80 \\ 80 & 80 & 80 & 85 & 85 \\ 85 & 85 & 85 & 85 & 85 \\ 85 & 85 & 85 & 95 & \end{array}$

b. Rentang = Nilai terbesar - Nilai terkecil $=95-55$ $=40$

c. Banyak kelas interval

$$
\begin{aligned}
& =1+3,3 \log n \\
& =1+3,3(\log 34) \\
& =1+3,3(1,53) \\
& =6,04 \text { atau } 6
\end{aligned}
$$

Jadi, banyak kelas yang diambil 6 (enam) kelas.

d. Panjang kelas interval

$$
\begin{aligned}
& =\frac{\operatorname{Re} n \tan g}{\text { Banyakkelas }} \\
& =\frac{40}{6}
\end{aligned}
$$$$
=6,66 \text { atau } 7
$$

Jadi, panjang kelas yang diambil 7 (tujuh).

e. Membuat tabel distribusi frekuensi

Tabel 2

\section{Distribusi Frekuensi Nilai Kelas Eksperimen 2}

\begin{tabular}{|c|c|c|c|c|c|}
\hline Interval & $\mathbf{f}_{\mathbf{i}}$ & $\mathbf{x}_{\mathbf{i}}$ & $\mathbf{f}_{\mathbf{i}} \mathbf{x}_{\mathbf{i}}$ & $\mathbf{x}_{\mathbf{i}}{ }^{\mathbf{2}}$ & $\mathbf{f}_{\mathbf{i}} \mathbf{x}_{\mathbf{i}}{ }^{2}$ \\
\hline $55-61$ & 2 & 58 & 116 & 3364 & 6728 \\
\hline $62-68$ & 4 & 65 & 260 & 4225 & 16900 \\
\hline $69-75$ & 8 & 72 & 576 & 5184 & 41472 \\
\hline $76-82$ & 9 & 79 & 711 & 6241 & 56169 \\
\hline $83-89$ & 10 & 86 & 860 & 7396 & 73960 \\
\hline $90-96$ & 1 & 93 & 93 & 8649 & 8649 \\
\hline Jumlah & 34 & 453 & 2616 & 35059 & 203878 \\
\hline
\end{tabular}

Sumber: Pengolahan data primer 2018 
Dari tabel dan distribusi frekuensi hasil belajar kelas eksperimen tersebut, dapat dilihat frekuensi nilai dari tiap-tiap kelas interval kelas eksperimen dan nilai tengah dari tiap-tiap kelas interval yang memiliki frekuensi $\left(f_{i}\right)$ paling banyak terdapat pada kelas 83-89 sebanyak 10 siswa, sedangkan untuk kelas yang memiliki frekuensi terendah terletak pada kelas 90-96 sebanyak 1 siswa. Berikut data dalam diagram batang:

\section{Gambar 2}

Diagram Distribusi Frekuensi Hasil Belajar Kelas Eksperimen 2

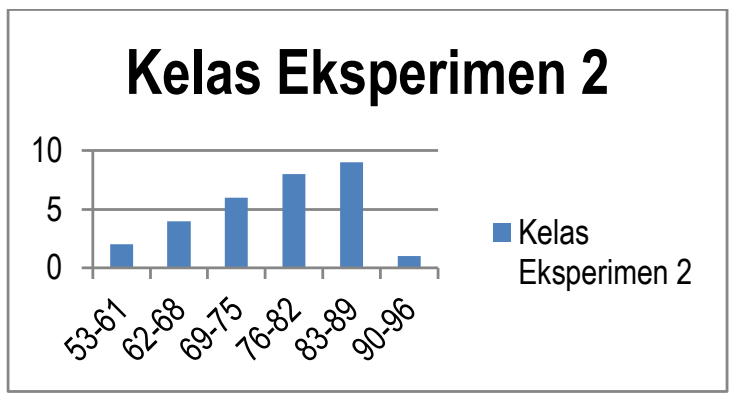

Nilai Kelas Interval

f. Nilai rata-rata kelas eksperimen

$$
\begin{aligned}
\bar{x} & =\frac{\sum f i x i}{\sum f i} \\
& =\frac{2616}{34} \\
& =76,94
\end{aligned}
$$

g. Mencari modus kelas eksperimen

$$
\begin{aligned}
\text { Mo } & =b+p\left[\frac{b 1}{b 1+b 2}\right] \\
b & =76-0,5=75,5 \\
p & =7 \\
b 1 & =10-9=1 \\
b 2 & =9-1=8 \\
M o & =75,5+7\left[\frac{1}{1+8}\right] \\
M_{0} & =75,5+7\left[\frac{1}{9}\right] \\
M_{0} & =75,5+7(0,1) \\
M_{0} & =75,5+0,7 \\
M_{0} & =76,2
\end{aligned}
$$

h. Mencari simpangan baku kelas eksperimen

$$
\begin{aligned}
S^{2} & =\frac{n \sum \mathrm{f}_{1} \mathrm{x}_{1}{ }^{2}-\left(\sum \mathrm{f}_{1} \mathrm{x}_{1}\right)^{2}}{n(n-1)} \\
S^{2} & =\frac{34(203878)-(2616)^{2}}{34(34-1)} \\
S^{2} & =\frac{6931852-6843456}{1122} \\
S^{2} & =\frac{88396}{1122} \\
S^{2} & =78,78 \\
S^{2} & =\sqrt{78,78} \\
S^{2} & =8,87
\end{aligned}
$$

Dari rata-rata, modus, dan simpangan baku maka dapat dicari koefisien kemiringan kurva dengan menggunakan rumus Karl Pearson, yaitu:

$$
\begin{aligned}
\mathrm{Km} & =\frac{\bar{X}-M_{O}}{S} \\
\mathrm{Km} & =\frac{76,94-76,2}{8,87} \\
\mathrm{Km} & =\frac{1,0}{8,87} \\
\mathrm{Km} & =0,12
\end{aligned}
$$

Dari perhitungan diatas, nilai $\mathrm{Km}$ adalah 0,12 dan Km terletak diantara (-1) dan (1), maka data kelas eksperimen dapat dikatakan terdistribusi normal.

\section{Uji Homogenitas Data}

Di samping pengujian terdapat normal tidaknya distribusi data pada sampel, perlu kiranya peneliti melakukan pengujian terhadap kesamaan (homogenitas) beberapa bagian sampel, yakni seragam tidaknya varias sampel yang diambil dari populasi yang sama. Uji homogenitas dalam penelitian ini peneliti menggunakan tes Barlett.

Tabel 3

Pengujian Homogenitas

\begin{tabular}{|c|c|c|c|c|c|}
\hline Sampel & $\begin{array}{c}\text { Dk = } \\
\text { n-1 }\end{array}$ & $\mathbf{S}^{2}$ & $\begin{array}{c}\text { Log } \\
\mathbf{S}^{2}\end{array}$ & $\begin{array}{c}\text { Dk. } \\
\text { Log S }\end{array}$ & Dk. S \\
\hline $\begin{array}{c}\text { Kelas } \\
\text { Eksperimen 1 }\end{array}$ & 34 & 86,16 & 1,93 & 65,62 & 2929,44 \\
\hline $\begin{array}{c}\text { Kelas } \\
\text { Eksperimen 2 }\end{array}$ & 34 & 78,78 & 1,89 & 64,26 & 2678,52 \\
\hline Jumlah $(\Sigma)$ & 68 & 242,16 & 3,82 & 129,88 & 295622,52 \\
\hline
\end{tabular}

Sumber: Pengelolahan data primer 2021

a) Perhitungan varians gabungan dari kedua sampel yaitu dengan rumus: 


$$
\begin{aligned}
& \mathrm{S}^{2}=\frac{\left(n 1 \cdot S_{1}^{2}\right)+\left(n 2 \cdot S_{2}^{2)}\right.}{n_{1}+n_{2}} \\
& \mathrm{~S}^{2}=\frac{(34 \cdot 9,28)+(34 \cdot 8,37)}{34+34} \\
& \mathrm{~S}^{2}=\frac{315,52+301,58}{68} \\
& \mathrm{~S}^{2}=\frac{617,1}{68} \\
& \mathrm{~S}^{2}=9,07
\end{aligned}
$$

b) Menghitung $\log S=\log 9,07=0,95$

c) Menghitung nilai $\beta=(\log S) \times \sum\left(n_{1}-1\right)=$ $0,95 \times 68=64,6$

d) Menghitung nilai $x^{2}$ hitung yaitu dengan rumus:

$$
\begin{aligned}
X^{2} & =(\ln 10) \cdot\left(\beta-\sum(d k) \log S\right) \\
& =(\ln 2,3) \cdot(129,88-64,6) \\
& =(2,3) \cdot(65,28) \\
& =150,144
\end{aligned}
$$

e) Bandingkan $x^{2}$ hitung dengan nilai $x^{2}$ hitung untuk $a=0,05$ dari derajat kebebasan (dk) $=\mathrm{k}-1=2-1=1$, maka dicari pada tabel chi- kuadrat didapat $x^{2}$ tabel $=3,84$ dan $x^{2}$ hitung $=150,144$ dan diketahui syarat homoginitas $=x^{2}$ hitung $<x^{2}$ tabel, maka di dapat $1,150,144<3,84$. Dari hasil perhitungan dapat disimpulkan bahwa sampel berasal dari populasi yang sama. Jadi data penelitian yang diperoleh dari kelas eksperimen 1 maupun kelas eksperimen 2 mengikuti distribusi normal/homogen.

Jika $x^{2}$ hitung $>x^{2}$ tabel berarti tidak homogen dan Jika $x^{2}$ hitung $<x^{2}$ tabel berarti homogen.

Setelah melakukan uji normalitas data uji homogenitas ternyata kedua pengujian menunjukkan masing-masing variabel telah homogen dan normal. Oleh sebab itu tes ini dapat dianalisis selanjutnya.

\section{Uji Hipotesis}

Setelah pengujian normalitas data maka dinyatakan terdistribusi normal, maka tahapan selanjutnya yang dilakukan adalah pengujian hipotesis penelitian dengan menggunakan statistik parametris Uji-t:

$$
\mathrm{t}=\frac{\bar{X}_{1}-\bar{X}_{2}}{\sqrt[S]{\left(\frac{1}{n_{1}}+\frac{1}{n_{2}}\right)}}
$$

Dengan

$$
S^{2}=\frac{\left(n_{1}-1\right) S_{1}^{2}+\left(n_{2}-1\right) S_{2}^{2}}{n_{1}+n_{2}-2}
$$

Kriterial pengujian hipotesis dalam penelitian ini diterima $\mathrm{H}_{a}$ jika thitung $>t_{\text {tabel(1-a) }}$

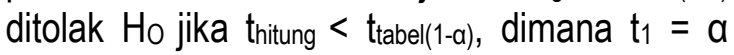
adalah terdapat dari distribusi dengan $\mathrm{dk}=\mathrm{n}_{1}+$ $\mathrm{n}_{2}$ - 2 dan peluang $(1-\mathrm{a})$. Dari perhitungan sebelumnya diperoleh nilai rata-rata data simpangan baku untuk kelas eksperimen 1 dan kelas eksperimen 2 .

\section{Tabel 4}

\section{Nilai Rata-rata dan Simpangan Baku}

\begin{tabular}{|c|c|c|c|c|c|}
\hline Sampel & $\begin{array}{c}\text { Dk = } \\
\text { n-1 }\end{array}$ & $\mathbf{S}^{2}$ & $\begin{array}{c}\text { Log } \\
\mathbf{S}^{2}\end{array}$ & $\begin{array}{c}\text { Dk. } \\
\text { Log S }\end{array}$ & Dk. S \\
\hline $\begin{array}{c}\text { Kelas } \\
\text { Eksperimen 1 }\end{array}$ & 34 & 86,16 & 1,93 & 65,62 & 2929,44 \\
\hline $\begin{array}{c}\text { Kelas } \\
\text { Eksperimen 2 }\end{array}$ & 34 & 78,78 & 1,89 & 64,26 & 2678,52 \\
\hline Jumlah $(\Sigma)$ & 68 & 242,16 & 3,82 & 129,88 & 295622,52 \\
\hline
\end{tabular}

Sumber: Pengelolah Data Primer 2021

Kemudian masukan nilai tersebut dalam rumus:

$$
\begin{aligned}
& S^{2}=\frac{\left(n_{1}-1\right) S_{1}^{2}+\left(n_{2}-1\right) S_{2}^{2}}{n_{1}+n_{2}-2} \\
& S^{2}=\frac{(34-1) 86,16+(34-1) 78,78}{34+34-2} \\
& S^{2}=\frac{(33) 86,16+(33) 78,78}{66} \\
& S^{2}=\frac{2843,28+2599,74}{66} \\
& S^{2}=\frac{5443,02}{66} \\
& S^{2}=82,47 \\
& S^{2}=\sqrt{82,47} \\
& S^{2}=9,08
\end{aligned}
$$

Kemudian thitung dicari dengan

$$
\begin{aligned}
& \mathrm{t}=\frac{\bar{X}_{1}-\bar{X}_{2}}{S \sqrt{\left(\frac{1}{n_{1}}+\frac{1}{n_{2}}\right)}} \\
& \mathrm{t}=\frac{83,32-76,94}{9,08 \sqrt{\left(\frac{1}{34}+\frac{1}{34}\right)}} \\
& \mathrm{t}=\frac{6,38}{9,08 \sqrt{0,04}}
\end{aligned}
$$


$t=\frac{6,38}{9,08(0,2)}$

$t=\frac{6,38}{1,81}$

$t=3,52$

Untuk mencari tabel untuk $\mathrm{t}(1-\mathrm{a})$ adalah:

$d k=n_{1}+n_{2}-2$

$d k=34+34-2$

$d k=66$

Jadi thitung $=3,52$ sedangkan tabel (66), terdaftar dalam tabel distribusi $t$, berdasarkan perhitungan tersebut, tabel (66) diperoleh sebesar 1,671 sedangkan thitung 3,52 dengan taraf signifkan 0,05 lebih besar dibandingkan dengan tabel 1,671 jadi hasil perhitungan didapat $3,52>1,671$. Maka dapat disimpulkan ada perbedaan penggunaan model pembelajaran Student teams Achievamant Division dengan model pembelajaran Jigsaw terhadap hasil belajar siswa dimana nilai rata-rata kelas eksperimen 1 lebih besar dibandingkan dengan kelas eksperimen 2.

\section{Pembahasan}

Dalam melakukan penelitian ini untuk mengumpulkan data yang diperlukan peneliti menggunakan alat pengumpul data berupa instrumen tes atau memalui tes soal. Setelah memperoleh data hasil tes siswa maka peneliti melakukan analisa data tes tersebut. Analisa data dilakukan dengan menggunakan rumus Uji-t melalui uji normalitas data. Uji normalitas data dilakukan peneliti untuk mengetahui normal atau tidaknya suatu penyebaran data. Maka dari itu, berdasarkan perhitungan yang didapat untuk kelas eksperimen 1, uji normalitas data yang diperoleh $\mathrm{Km}=-0,51$ dan harga tersebut terletak antara (-1) dan (1) sehingga dapat dikatakan bahwa data kelas eksperimen 1 terdistribusi normal. Sedangkan uji normalitas data yang diperoleh pada kelas eksperimen 2, uji normalitas yang didapat $\mathrm{Km}=0,12$ dan harga tersebut terletak antara (-1) dan (1) sehingga dapat dikatakan bahwa data di kelas eksperimen 2 terdistribusi normal. Jadi, data penelitian yang telah dilakukan dari kelas X IPS 1atau eksperimen 1 dan kelas X IPS 2 atau eksperimen 2 mengikuti distribusi normal.
Selanjutnya setelah pengujian normalitas data, data tersebut dinyatakan terdistribusi normal, maka tahapan berikutnya yang dilakukan adalah pengujian hipotesis penelitian dengan menggunakan statistik parametris yaitu rumus Uji-t dengan kreteria pengujian $\mathrm{H}_{\mathrm{a}}$ diterima jika thitung $>$ dari tabel(1-a) dan $\mathrm{H}_{0}$ ditolak jika thitung $<$ dari tabel(1-a).

Hasil analisa data menunjukkan bahwa hasil tes akhir maka diperoleh thitung $=3,15$ dan tabel dengan taraf nyata $5 \%$ dan dk $=66$ diperoleh $t_{\text {tabel }} 1,671$. Dengan demikian ternyata $t_{\text {hitung }}>t_{\text {tabel, }}$ maka hipotesis tentang ada perbedaan penggunaan model pembelajaran Student Team Achievamant Division dengan model pembelajaran Jigsaw terhadap hasil belajar siswa pada mata pelajaran sejarah kelas $X$ di SMA Negeri 2 Mesuji tahun pelajaran 2020/2021 diterima oleh hasil analisis tersebut. Penggunaaan model pembelajaran Student Team Achievamant Division yang digunakan di kelas X IPS 1 atau eksperimen 1 mampu menciptakan suasana dalam proses belajar mengajar di kelas menyenangkan dan membuat siswa lebih mudah memahami materi pelajaran sejarah dan mendorong siswa lebih aktif sehingga mampu meningkatkan hasil belajar siswa, maka dari itu penggunaan model pembelajaran Student Team Achievamant Division memberikan perbedaan terhadap hasil belajar siswa yang dilihat dari hasil tes soal pilihan ganda yang telah diujikan di kelas X IPS 1 dari seluruh 34 siswa. Siswa yang mendapatkan nilai tertinggi (95) yaitu 6 siswa dan siswa yang mendapatkan nilai terendah (55) yaitu hnya 1 siswa.

Sedangkan dari penggunaan model pembelajaran Jigsaw yang digunakan di kelas $X$ IPS 2 atau eksperimen 2 sama-sama mampu menciptakan suasana kelas menjadi menyenangkan dan mampu mendorong siswa untuk memahami materi yang diajarkan, namun saat dilakukan ujian tes pilihan ganda yang dilakukan di kelas X IPS 2 dari seluruh siswa 34, siswa yang mendapatkan nilai tertinggi (95) yaitu 1 siswa dan siswa yang mendapatkan nilai terendah (55) yaitu hanya 1 siswa. 


\section{SIMPULAN}

Berdasarkan hasil penelitian yang telah dilaksanakan di SMA Negeri 2 Mesuji dapat disimpulkan ada perbedaan penggunaan model pembelajaran Student Teams Achievamant Division dengan model pembelajaran Jigsaw terhadap hasil belajar siswa pada mata pelajaran sejarah kelas $X$ di SMA Negeri 2 Mesuji tahun pelajaran 2020/2021. Tes pilihan ganda yang telah diuji kevaliditasan dan reliabilitasannya, distribusi nilai frekuensi, pengujian homogenitas, dan nilai rata-rata simpang baku. Dari beberapa pengujian yang telah dilakukan pada kelas X IPS 1 dan X IPS 2, didapatkan nilai kelas X IPS 1 atau eksperimen 1 yang menggunakan model pembelajaran Student Teams Achievamant Division lebih tinggi dibandingkan hasil kelas X IPS 2 yang menggunakan model pembelajaran Jigsaw.

\section{DAFTAR PUSTAKA}

Arikunto, S. 2013. Prosedur Penelitian. Jakarta: PT Rineka Cipta.

Isjoni. 2014. Cooprative Learning. Bandung: Alfabeta.
Ismaya. 2015. Pengelolaan Pendidikan. Bandung: Refika Aditama.

Octavia, S. A. 2020. Model-Model Pembelajaran. Yogyakarta: CV Budi Utama.

Pohan, A. E. 2020. Konsep Pembelajaran Daring Berbasis Pendekatan IImiah. Purwodadi: CV Sarnu Untung.

Shoimin, A. 2014. 68 Model Pembelajaran Inovatif dalam Kurikulum 2013. Yogyakarta: Ar-Ruzz Media.

Sugiyono. 2012. Metode Penelitian dan Pendidikan. Bandung: Alfabeta.

Tirtahardja, U., \& Sulo, L. 2005. Pengantar Pendidikan. Jakarta: PT Rineka Cipta.

Wahyudin, D. 2007. Pengantar Pendidikan. Jakarta: Universitas Terbuka Depertemen Pendidikan Nasional. 


\section{KETENTUAN PENULISAN ARTIKEL JURNAL KALPATARU}

1. Naskah berbahasa Indonesia yang disempurnakan bertemakan kesejarah yang meliputi hasil penelitian sejarah, pengajaran sejarah dan penelitian kebudayaan.

2. Naskah harus asli dan belum pernah dimuat dalam media lain. Naskah dapat berupa hasil penelitian/artikel kajian konseptual yang ditulis oleh perorangan dan atau kelompok.

3. Naskah ditulis dengan cara-cara yang sesuai dengan ketentuan penulisan artikel ilmiah menggunakan bahasa Indonesia yang baku, berupa ketikan, beserta soft file dalam CD-RW atau dengan mengirimkan email pada redaksi jurnal Kalpataru dengan alamat jurnalkalpatarusejarah@gmail.com, spasi tunggal, jenis huruf arial narrow ukuran 12, dengan panjang naskah antara 8-15 halaman pada kertas A4.

4. Artikel hasil penelitian memuat:

JUDUL

Nama Penulis

Abstrak

A. PENDAHULUAN

B. METODE PENELITIAN

C. HASIL DAN PEMBAHASAN

D. SIMPULAN

DAFTAR PUSTAKA
: XXX (HURUF KAPITAL)

: (disertai jabatan, institusi, dan email)

: (Bahasa Indonesia yang memuat 100-200 kata diikuti kata kunci, dengan jenis huruf arrial narrow dan ukuran huruf 11 serta dicetak miring).

: (memuat latar belakang masalah, tinjauan pustaka secara ringkas, masalah penelitian, dan tujuan penelitian).

5. Artikel Kajian Konseptual memuat:

JUDUL

Nama Penulis

Abstrak

PENDAHULUAN

Sub Judul

Simpulan

DAFTAR PUSTAKA
: (berisi simpulan).

: (berisi pustaka yang dirujuk dalam uraian naskah).

6. Referensi sumber dalam teks artikel ditulis dengan menggunakan side note, contoh (Jalaludin, 1991:79); sementara penulisan daftar pustaka disusun dengan ketentuan. Nama pengarang. Tahun terbit. Judul (dicetak miring). Kota terbit: Nama Penerbit. Contoh: Koentjaraningrat. 2010. Manusia dan Kebudayaan di Indonesia. Jakarta: Djambatan. Daftar pustaka hanya memuat pustaka/sumber yang dirujuk dalam uraian dan disusun menurut abjad tanpa nomor urut.

7. Naskah yang dimuat akan disunting kembali oleh redaksi tanpa mengubah isinya.

8. Naskah yang ditolak (tidak bisa dimuat) akan dikirim kembali ke penulis dengan pemberitahuan tertulis dari redaksi atau melalui email.

9. Penulis yang naskahnya dimuat akan mendapat 1 (satu) majalah nomor yang bersangkutan.

10.Kontak person: Muhamad Idris (081271498618); Eva Dina Chairunisa (082281267851); Jeki Sepriady (085269261780). 